\title{
Selective Oxidation Using Flame Aerosol Synthesized Iron and Vanadium-Doped Nano-TiO 2
}

\author{
Zhong-Min Wang, ${ }^{1}$ Endalkachew Sahle-Demessie, ${ }^{2}$ and Ashraf Aly Hassan ${ }^{2}$ \\ ${ }^{1}$ Environmental Health Laboratory, California Department of Public Health, 850 Marina Bay Parkway, EHLB/G365, Richmond, \\ CA 94804, USA \\ ${ }^{2}$ U.S. Environmental Protection Agency, Office of Research and Development, National Risk Management Research Laboratory, \\ Cincinnati, OH 45268, USA
}

Correspondence should be addressed to Endalkachew Sahle-Demessie, sahle-demessie.endalkachew@epa.gov

Received 20 December 2010; Accepted 13 April 2011

Academic Editor: Mallikarjuna Nadagouda

Copyright (๑) 2011 Zhong-Min Wang et al. This is an open access article distributed under the Creative Commons Attribution License, which permits unrestricted use, distribution, and reproduction in any medium, provided the original work is properly cited.

\begin{abstract}
Selective photocatalytic oxidation of 1-phenyl ethanol to acetophenone using titanium dioxide $\left(\mathrm{TiO}_{2}\right)$ raw and doped with Fe or $\mathrm{V}$, prepared by flame aerosol deposition method, was investigated. The effects of metal doping on crystal phase and morphology of the synthesized nanostructured $\mathrm{TiO}_{2}$ were analyzed using XRD, TEM, Raman spectroscopy, and BET nitrogen adsorbed surface area measurement. The increase in the concentration of $\mathrm{V}$ and Fe reduced the crystalline structure and the anatase-to-rutile ratios of the synthesized $\mathrm{TiO}_{2}$. Synthesized $\mathrm{TiO}_{2}$ became fine amorphous powder as the $\mathrm{Fe}$ and $\mathrm{V}$ concentrations were increased to 3 and $5 \%$, respectively. Doping $\mathrm{V}$ and $\mathrm{Fe}$ to $\mathrm{TiO}_{2}$ synthesized by the flame aerosol increased photocatalytic activity by 6 folds and 2.5 folds, respectively, compared to that of pure $\mathrm{TiO}_{2}$. It was found that an optimal doping concentration for $\mathrm{Fe}$ and $\mathrm{V}$ were $0.5 \%$ and $3 \%$, respectively. The type and concentration of the metal dopants and the method used to add the dopant to the $\mathrm{TiO}_{2}$ are critical parameters for enhancing the activity of the resulting photocatalyst. The effects of solvents on the photocatalytic reaction were also investigated by using both water and acetonitrile as the reaction medium.
\end{abstract}

\section{Introduction}

Titanium dioxide $\left(\mathrm{TiO}_{2}\right)$ is a photocatalyst that is used for various applications; such as wastewater and air treatments, virus disinfection and water splitting due to its low cost and its high activity and stability under irradiation. However, $\mathrm{TiO}_{2}$ has a large band gap energy $(3.2 \mathrm{eV})$ that prohibits the use of visible light to activate it and requires UV light of wavelength ranging $320 \sim 400 \mathrm{~nm}$ to generate electronhole pairs. Searching for semiconductors that absorbs large portion of solar spectrum reaching the earth has been intensified. Recently, there has been increasing interest in doping $\mathrm{TiO}_{2}$ with transition metal or nonmetal species, such as nitrogen and sulfur, to narrow or shift the band gap in order to activate the catalyst using visible light [1-6]. Doping metals in $\mathrm{TiO}_{2}$ matrix could increase the photocatalytic performance of $\mathrm{TiO}_{2}$ with irradiation both UV and visible light because of better conducting characteristics. Metal doping can also change the physical properties, such as lifetime of electron-hole pair and adsorption characteristics. Various transition metals have been used as doping materials [7-11], and many systems have been tested for potential commercial applications $[1,6]$ as well as improving photocatalyst activity of $\mathrm{TiO}_{2}$ in visible light range [12-18].

However, the effects of metal doping on catalytic properties of the $\mathrm{TiO}_{2}$ are not conclusive. There are also no general guidelines to be followed in the selection of metal species or the methods of photocatalyst preparation that would result in improved activity. Although doping with transition metals at low concentrations has positive effects on the photocatalytic activity of $\mathrm{TiO}_{2}[19,20]$, some dopants have shown adverse effects $[1,21]$. There is a progressive shift of the light absorption threshold toward the visible light range when increasing amounts of cations $\mathrm{M}^{+n}(\mathrm{M}: \mathrm{Cr}, \mathrm{V}, \mathrm{Fe}$, Co), but no improvement of the photoactivity of the system was observed [22]. Metal doping of $\mathrm{TiO}_{2}$ with $\mathrm{Cr}^{3+}$ and $\mathrm{Mo}^{5+}$ 
ions have shown to narrow the band gap of $\mathrm{TiO}_{2}$, change other physical properties such as the lifetime of electron-hole pairs and adsorption characteristics of the catalyst [23]. The presence of doping species either on the surface or in the lattice and the method how the metal species is deposited or combined with the $\mathrm{TiO}_{2}$ are critical to photocatalytic activity. Doping metal species in the matrix has been suggested to create a hole-trap or an electron-hole recombination center rather than an electron trap. Dvoranová et al. [24] suggested that transition metals should be coated mainly on the surface of the photocatalyst to form an electron trap and hence promote photocatalysis, although their results are inconclusive. The difference in results could be derived from differences in preparation methods, synthesis conditions, and position of doped species on the surface or in the crystal lattice structure of $\mathrm{TiO}_{2}$ [25]. Overload metal species on $\mathrm{TiO}_{2}$ promote either phase change [26] or recombination of the electron-holes by dramatically changing conductivity of materials [27], becoming detrimental to the photocatalytic activity. Therefore, optimal dopant concentration is usually reported for the best photocatalyst performance [27-32].

Flame aerosol synthesis of nanoparticles have been used for large-scale manufacturing of ceramic powders such as pigmentary $\mathrm{TiO}_{2}$, fumed silica, and alumina [33]. Advances in this field has allowed the production of more complex products with high functionality including molecular doping of small quantities of materials in the preparation of ceramic materials [34]. The technology has been used to produce highly active nanostructured coatings with closely controlled morphology and composition $[33,35,36]$. Flame synthesis technology could be a more effective way to make versatile and low cost nanostructured materials, such as carbon nano-tubes [37]. This study aims to synthesize metal-doped nanostructured catalysts using the flame aerosol technology and test the effect of doping on photo-activities of the resulted nanostructured catalysts. In this study photocatalytic performance of $\mathrm{Fe}$ or $\mathrm{V}$ doped $\mathrm{TiO}_{2}$ synthesized using flame aerosol process in addition to further characteristics are presented. Iron was chosen because of its low toxicity and the wide availability of data as a doping material. Studies indicated that $\mathrm{V}$ is one of the promising doping materials $[34,38,39]$, therefore it is a good choice as a doping material.

Selective catalytic oxidation of alcohols to carbonyls is one of the most important chemical transformations in chemical industry. Acetophenone is the simplest aromatic ketone with a melting point of $20^{\circ} \mathrm{C}$ and has low water solubility. It is an important intermediate in chemical and pharmaceutical industries. It is used for fragrance in soaps and perfumes, as a flavoring agent in food, and as a solvent for plastics and resins. In addition, it is used as a polymerization catalyst for the manufacture of olefins, as an intermediate for pharmaceuticals, agrochemicals, and other organic compounds as well as a drug to induce sleep.

Commercial acetophenone production involves FriedelCrafts acylation of benzene with acetic anhydride or acetyl chloride. Friedel-Craft alkylation is commonly condensed using homogeneous acid catalysts such as aluminum chloride at more than stoichiometric amounts with acetyl chloride as the acylating agent. This process may create pollution problems related to the disposal of the catalyst and treatment of acidic effluent. It can be also obtained by air oxidation of ethyl benzene, as a by-product of cumene or from acrylonitrile.

Dehydrogenation of secondary alcohol is usually carried out using chromic acid or sulfuric acid with potassium dichromate. However, in the current work, a simple process was developed based on the utilization of heterogeneous catalysts to produce acetophenone by photocatalytic oxidation of 1-phenylethanol. The photooxidation process is cleaner than the conventional synthetic method since the reaction by-product is water, and the photocatalyst can be easily recycled back to the reaction system. The oxidation of 1-Phenylethanol was selected as a probe molecule for this study. There are studies that have shown that the preparation methods of meta-doped $\mathrm{TiO}_{2}$ can be critical in promoting the photoactivity [40].

\section{Experimental}

2.1. Materials and Preparation of Metal-Doped $\mathrm{TiO}_{2}$ using Flame Aerosol Methods. Schematic diagram of the flame aerosol synthesis system for preparing the pure and vanadium doped- $-\mathrm{TiO}_{2}$ is shown in Figure $1(\mathrm{a})$. The system consists of a diffusion burner, an atomizer for generating aerosol from the titanium (IV) Isopropoxide (TTIP) (97\% Aldrich Chemical) a precursor for $\mathrm{TiO}_{2}$, a water-cooled stainless steel plate for collecting the products. Mass flow controllers were used to adjust the flow rates of methane, oxygen, and air. The organic form of the vanadium, vanadium (V) oxy-tripropoxide (98\%, Aldrich Chemical), was easily dissolved in TTIP in the atomizer at preset ratios. The mixture of precursors flowed to the flame through the center port of the diffusion burner. Methane and oxygen were fed through the second and outer ports, respectively. Schematic diagram of the flame aerosol reactor system for preparing iron-doped titanium dioxide is shown in Figure 1(b). A solution of $\mathrm{Fe}\left(\mathrm{NO}_{3}\right)_{3}$ was used as the iron source since it is more stable and less volatile than Fe carbonyl. Varying concentrations of the iron nitrate water solution were used to obtain desired amounts of Fe doping. Water was removed from the flow via diffusion dryer before aerosols reach the flame reactor to avoid quenching and allow better control of the flame temperature that may result in forming big clump in the transport tube. Earlier experiments indicated that in the case of Fe doping the stream bearing precursor material has to flow through the out port of the burner to generate higher anatase-to-rutile ratio in the $\mathrm{TiO}_{2}$. The $\mathrm{TiO}_{2}$ precursor and oxygen were introduced through the center port of the burner and methane flowed through the middle annular tube. The precursor oxidized in the flame and metal-doped $\mathrm{TiO}_{2}$ was deposited on a water-cooled stainless steel plate placed above the flame and controlled by an automatic rotating frame support. The flame temperatures were controlled by adjusting the gas flow rates and controlling the fuel-to-air ratios. The quench temperature profile was adjusted by controlling the rotating speed and the cooling water flow rate into the cooling plate. The quenching temperature affected the particle size and the morphology of 


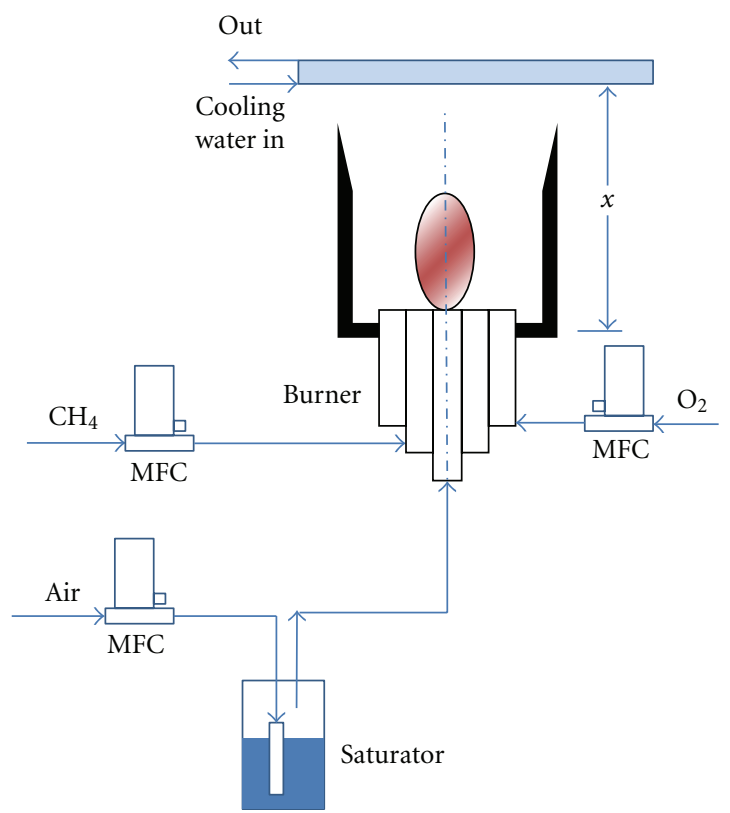

Precursor:

Titanium isopropoxide

Vanadium oxytripropoxide

(a)

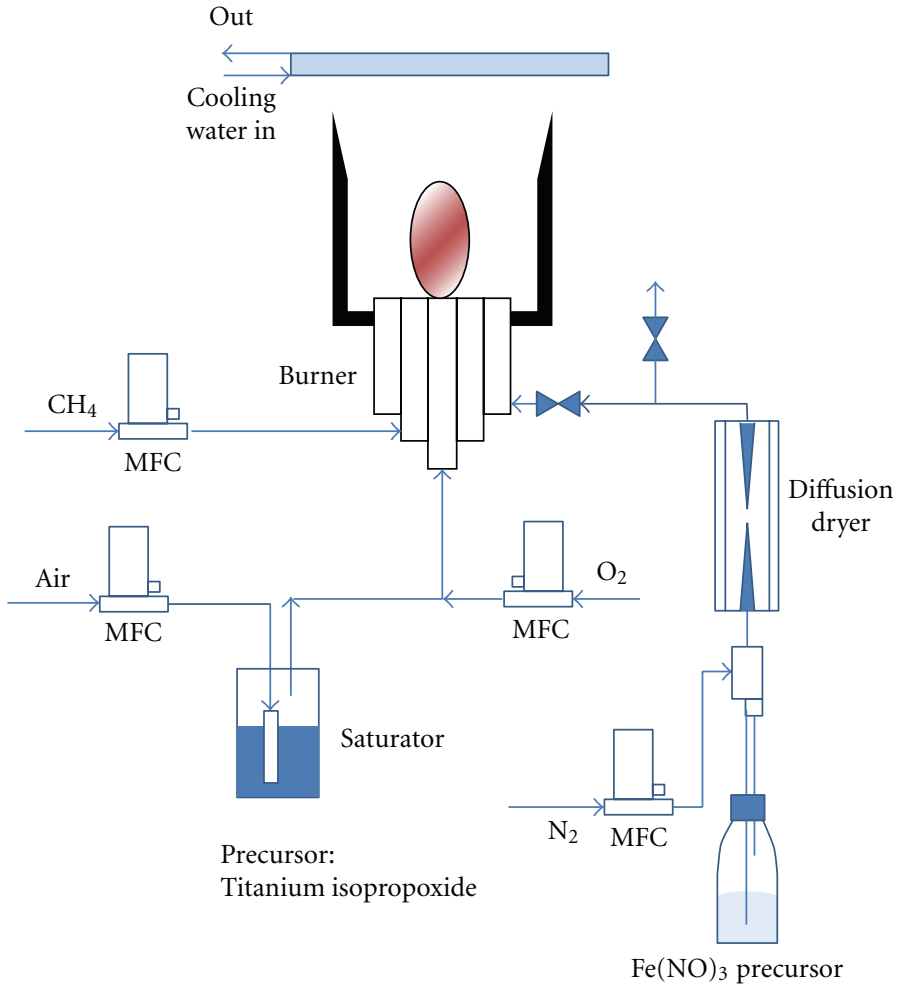

(b)

FIgURE 1: Multiannular coflow diffusion burner for synthesizing nanostructured $\mathrm{TiO}_{2}$ with (a) vanadia doped, (b) Fe doped.

TABLE 1: Typical flame synthesis condition for the metal doped $\mathrm{TiO}_{2}$.

\begin{tabular}{lccc}
\hline Flow & Pure $\mathrm{TiO}_{2}$ & V-doped $\mathrm{TiO}_{2}$ & $\mathrm{Fe}$-doped $\mathrm{TiO}_{2}$ \\
\hline $\mathrm{CH}_{4}(\mathrm{~L} / \mathrm{m})$ & 1.00 & 1.00 & 1.13 \\
$\mathrm{O}_{2}(\mathrm{~L} / \mathrm{m})$ & 1.00 & 1.00 & 1.00 \\
Air $(\mathrm{L} / \mathrm{m})$ & 3.88 & 3.88 & 3.88 \\
Doping flow $(\mathrm{L} / \mathrm{m})$ & - & - & 0.30 \\
\hline
\end{tabular}

the $\mathrm{TiO}_{2}$ particles. The position of the cooling plate above the flame determined the reaction time of the $\mathrm{TiO}_{2}$ precursor in the flame, which is a critical parameter to determine the primary particle size and the characteristics of the flamesynthesized $\mathrm{TiO}_{2}$. A large number of preliminary tests, XRD, and Raman spectroscopy measurements were conducted to determine suitable operation conditions that afforded for desired crystalline structure, form, particle size, and doping concentrations of $\mathrm{TiO}_{2}$. The typical experiment conditions for the flame aerosol synthesis process are shown in Table 1.

2.2. Characterization of the Synthesized Samples. X-ray diffraction pattern of powder samples of metal-doped $\mathrm{TiO}_{2}$ were characterized by XRD (Rigaku D-2000) for recording and for determining the crystal structure. Transmission Electron Microscopy (TEM) (Philips, PW6060) was used to determine the surface morphology and particle size of the doped catalysts. The BET surface area was measured by AutoChem 2920 (Micromeritics, Atlanta, GA). Bulk doping concentrations of the metal species in the synthesized photocatalysts were determined by inductively coupled plasma (ICP) emission spectroscopy (Perkin Elmer Optima $3300 \mathrm{DV})$.

2.3. Photocatalytic Reaction. Photocatalytic activities of neat, vanadium, or Fe-doped $\mathrm{TiO}_{2}$ were evaluated using oxidation of a probe molecule, 1-phenylethanol to acetophenone in two different solvents. All experiments employed the same light source. The reactions were performed in a $20 \mathrm{~mL}$ microbatch reactor equipped with Pen-Ray 5.5 Watts UV lamp (TM UVP, Inc. San Gabriel, CA). The irradiance at the reactor surface was $15 \mathrm{~mW} / \mathrm{cm}^{2}$ as measured with a photometer (International Light Inc. model IL 1400A). The schematic diagram of the microreactor system is shown in Figure 2. Neat and doped $\mathrm{TiO}_{2}(0.05 \mathrm{~g} / \mathrm{L})$ were suspended in the microreactor that contained $20 \mathrm{~mL}$ reaction medium with substrate concentration at $20 \mathrm{ppm}$. Water or acetonitrile were used as the reaction medium to study the effect of solvents. The mixture was well stirred during the reaction process using a magnetic stirrer. The UV lamp was place at the center of the reactor, and oxygen was supplied for the oxidation. Since adsorbed oxygen served as a trap for the photogenerated conduction band electron in many heterogeneous photocatalytic reactions [41], solvents were saturated with $\mathrm{O}_{2}$ prior to the reaction study. The reactions 


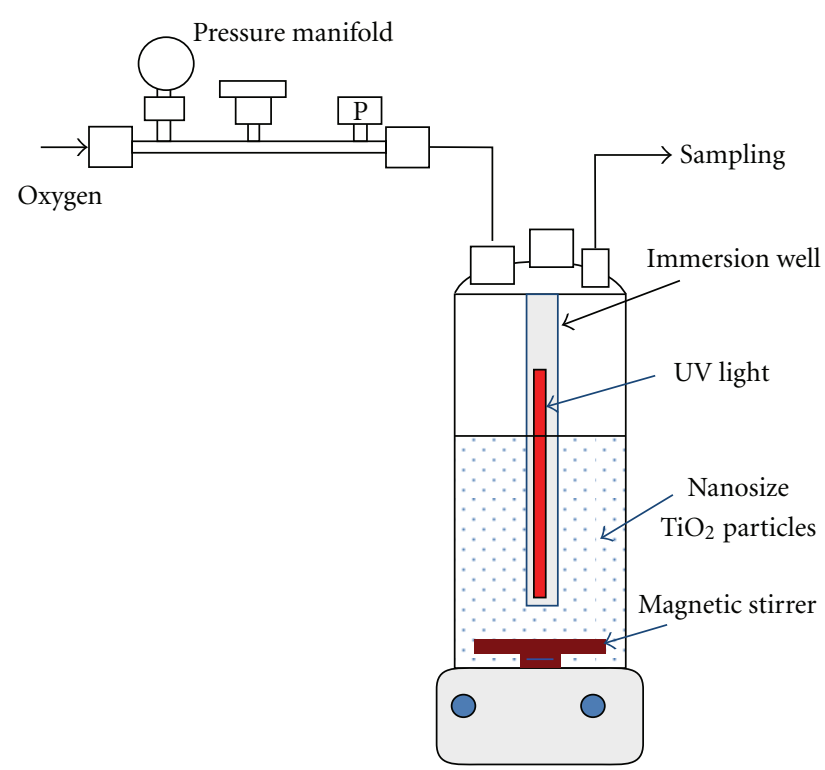

Figure 2: Schematic of the micro reactor system for photoxidation.

were conducted at room temperature and at atmospheric pressure. Control studies were made to measure the photocatalytic activity of neat flame synthesized anatase phase $\mathrm{TiO}_{2}$ and commercially available $\mathrm{TiO}_{2}$ from Degussa (P25). Liquid samples were collected through the reactor sample port at selected time intervals, and the mixtures were analyzed using a Hewlett-Packard 6890 gas chromatograph with a low-bleed HP-5MS $(30 \mathrm{~m} \times 0.25 \mathrm{~mm} \times 0.25 \mathrm{~mm})$ column and a split/splitless injector. A mass selective detector equipped with a quadrapole mass filter (Hewlett-Packard 5973) was used for detection of the samples. Quantification of the oxygenated products was obtained using a multipoint calibration curve for each product.

\section{Results and Discussion}

3.1. Structural Characteristics of Metal-Doped $\mathrm{TiO}_{2}$. The Xray diffraction patterns for neat $\mathrm{TiO}_{2}$ samples and for $\mathrm{Fe}-$ doped $\mathrm{TiO}_{2}$ with different $\mathrm{Fe}$ concentrations are shown in Figure 3. The primary crystalline structure of the pure $\mathrm{TiO}_{2}$ was the anatase phase. As the doped Fe concentration increased, the anatase $\mathrm{TiO}_{2}$ phase fraction decreased, reaching almost amorphous structure and losing its catalytic activity as the $\mathrm{Fe}$ concentration exceeded $2 \%$ in atom ratio. Similar XRD patterns were observed when the vanadium concentrations of the doped $\mathrm{TiO}_{2}$ increased beyond $4 \mathrm{wt} \%$. However, the concentrations of vanadium can reach as much high as $5 \%$ wt. before major changes in the crystal structure was detected. Other researchers have observed that niobium and vanadium stabilize the anatase crystalline form of $\mathrm{TiO}_{2}[27,42]$. No diffraction peaks originating from $\mathrm{V}_{2} \mathrm{O}_{5}$ crystallite were detected from the vanadium dispersed on the $\mathrm{TiO}_{2}$, which could be due to the presence of vanadyl groups $\left(\mathrm{V}^{4+}\right)$ or polymeric vanadates $\left(\mathrm{V}^{5+}\right)$. A previous study [26] has shown that the increase in the doped metal ion concentrations interferes in flame synthesis of $\mathrm{TiO}_{2}$ converting some of the anatase phase to rutile, and finally it became amorphous.

The Raman spectrum for the neat and $\mathrm{Fe}$-doped $\mathrm{TiO}_{2}$ are shown in Figure 4. A well-resolved Raman peak is seen at $153 \mathrm{~cm}^{-1}$, and three broader features are found in the highfrequency region located at around 415, 515, and $630 \mathrm{~cm}^{-1}$. In spite of their lower intensity and broader line width, all the Raman features observed in the spectra are close to those in the bulk anatase phase. The Raman spectra of the nanophase $\mathrm{TiO}_{2}$ after different amounts of $\mathrm{Fe}$ were doped is shown in Figure 4. One significant observation of these spectra is the reduced intensity of the lowest-frequency Eg mode with increased amounts of $\mathrm{Fe}$ and a shift in peak position of the $153 \mathrm{~cm}^{-1}$, indicating the decrease in the crystalline quality of the $\mathrm{TiO}_{2}$. Therefore, the result confirms XRD data that the neat $\mathrm{TiO}_{2}$ possesses higher degree of long-range order of anatase phase. However, with increase in Fe concentration the peak intensity attenuated gradually, and the weak overlapped broader peaks in the high-frequency region indicate that the short-range order is poor and optical phonons may decay as imperfect sites. Table 2 summarizes surface area changes for different doping concentrations of flamesynthesized $\mathrm{Fe}$-doped $\mathrm{TiO}_{2}$. As the doped $\mathrm{Fe}$ concentrations increased, the particles gradually lost crystalline structure and the products surface area increased. The surface area of vanadium-doped $\mathrm{TiO}_{2}$ also increased with increase in the amount of doping, shown in Table 3. Comparison of TEM images of pure $\mathrm{TiO}_{2}$, and $\mathrm{V}$ - or Fe- doped $\mathrm{TiO}_{2}$ suggested that the doped metal ions to be present on the top layers of the $\mathrm{TiO}_{2}$ particles shown as Figure 5. Ranjit and Viswanathan [31] have reported that the solid solution of $\mathrm{TiO}_{2}$ with doping materials in the top few layers of the surface promote the photocatalytic activity of the catalyst. Shah et al. [43] confirmed that photocatalytic efficiency of $\mathrm{TiO}_{2}$ can be enhanced by homogeneous doping of $\mathrm{Nd}^{3+}, \mathrm{Pd}^{2+}$, and $\mathrm{Pt}^{4+}$, but $\mathrm{Fe}^{3+}$ doping resulted in little or no improvements. TEM images show that when the doping concentration is not relatively high, both of the $\mathrm{Fe}$ - and $\mathrm{V}$-doped $\mathrm{TiO}_{2}$ have similar spherical shapes and uniform particle sizes ranging from 10 to $50 \mathrm{~nm}$. As the doping concentration increases the $\mathrm{TiO}_{2}$ particle sizes become smaller, more agglomerated, and resulting in larger surface areas and change of crystallinity.

3.2. Photocatalytic Oxidation of Aromatic Alcohol. In this study, the photocatalytic conversion oxidation of 1phenlyethanol to acetophenone was tested using undoped $\mathrm{TiO}_{2}$ prepared by flame aerosol method and from Degussa, Fe- and V-doped $\mathrm{TiO}_{2}$. Gas phase oxidation of 1-phenyl ethanol produced multiple products such as benzaldehyde, styrene, toluene, and acetophenone; however, in liquid phase acetophenone was the main product observed [44]. Therefore, the yield of acetophenone that is acetophenone produced/1-phenyl-ethanol consumed is more than 95\%. The initial reaction of photocatalytic oxidation 1phenylethanol takes place on the surface of $\mathrm{TiO}_{2}$, where the primary hole reaches the surface and interacts with the surface hydroxyl groups followed by an electron transfer to the hole to form species like $\mathrm{OH}^{\cdot}$ and $\equiv \mathrm{TiO}^{-}$[45]. These species react via a mediated pathway. At high alcohol 
<smiles>CC(=O)c1ccccc1</smiles><smiles>OC(Cl)c1ccccc1</smiles>

1-phenylethanol

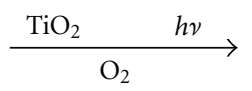<smiles>CC(=O)c1ccccc1</smiles>

Acetophenone

SCHEME 1

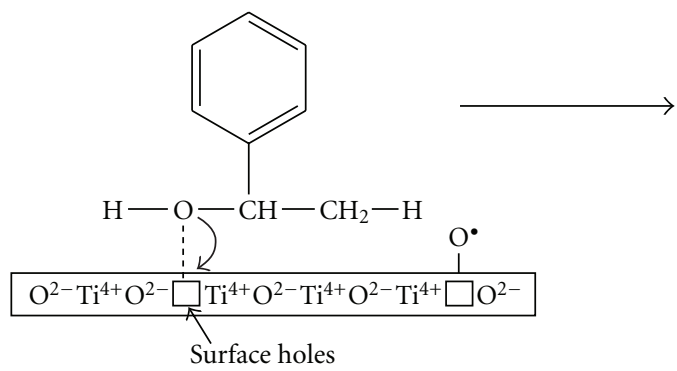<smiles>CC(=O)c1ccccc1</smiles>

Scheme 2: Photocatalytic oxidation of 1-phenyl ethanol to acetophenone over $\mathrm{TiO}_{2}$ ( $\square=$ surface hole).

TABLE 2: BET surface area of codeposited Fe-doped $\mathrm{TiO}_{2}$ prepared with flame aerosol method.

\begin{tabular}{lccc}
\hline Photocatalyst & Fe concentration $(\mathrm{wt} . \%)$ & BET surface area $\left(\mathrm{m}^{2} / \mathrm{g}\right)$ & $\%$ anatase \\
\hline Degussa & 0 & 51.0 & 82 \\
Flame-synthesized & 0 & 73.0 & 95 \\
Pure $\mathrm{TiO}_{2}$ & & & 80 \\
Fe-doped I & 0.55 & 83.4 & 52 \\
$\mathrm{Fe}-$ doped II & 1.18 & 94.6 & Amorphous \\
Fe-doped III & 3.0 & 143.6 & Amorphous \\
Fe-doped IV & 5.0 & 198.3 & \\
\hline
\end{tabular}

TABLE 3: BET surface area of codeposited Vanadium-doped $\mathrm{TiO}_{2}$ prepared with flame aerosol synthesis.

\begin{tabular}{lccc}
\hline Photocatalyst & V concentration $(\%)$ & BET surface area $\left(\mathrm{M}^{2} / \mathrm{g}\right)$ & $\%$ anatase \\
\hline Degussa & 0 & 51 & 82 \\
Flame-synthesized & 0 & 73 & 95 \\
Pure $\mathrm{TiO}_{2}$ & & & 90 \\
V-doped I & 1.78 & 64.7 & 86 \\
V-doped II & 3.00 & 68.3 & 63 \\
V-doped III & 4.47 & 90.6 & 57 \\
V-doped IV & 4.84 & 96.2 & Amorphous \\
V-doped V & 4.95 & 120.7 & \\
\hline
\end{tabular}




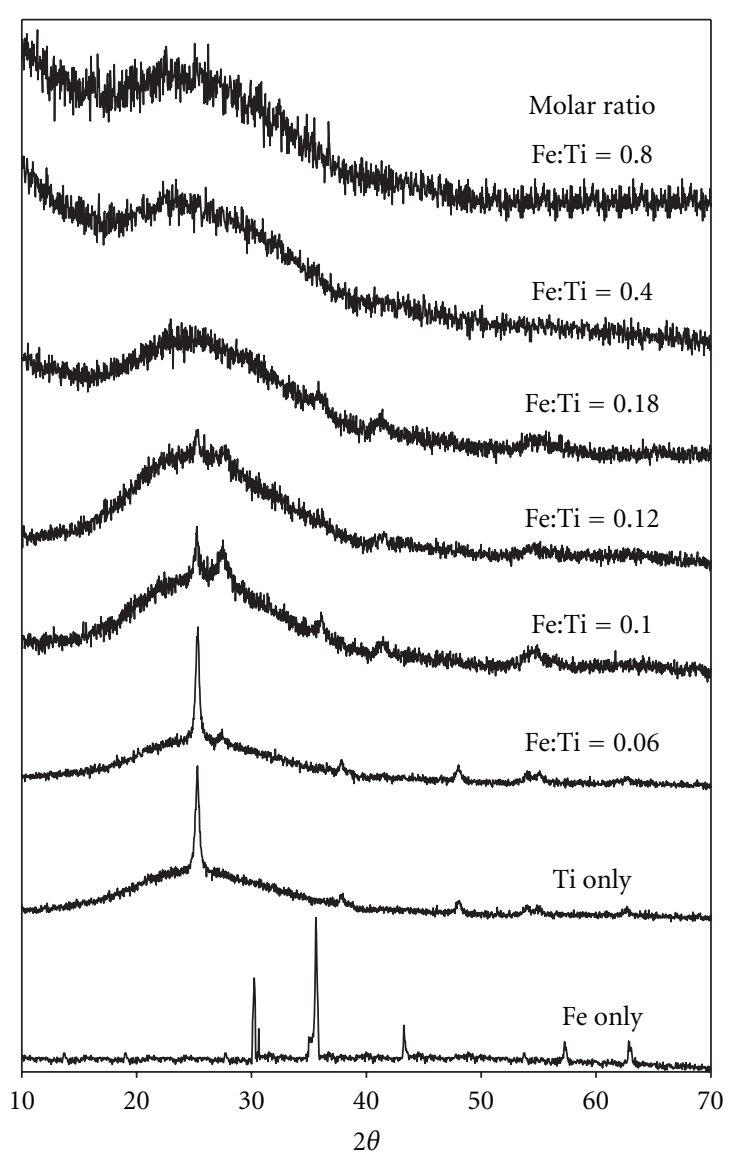

FIGURE 3: X-ray diffraction patterns of flame aerosol prepared iron deposited $\mathrm{TiO}_{2}$ at different doping concentrations.

concentration, which is the case, there could also be a direct interaction of the surface hole with the hydroxyl group of the alcohol [46]. In addition, alcohols may undergo dehydration on the catalyst surface during photocatalytic oxidation reaction $[47,48]$.

The initial photooxidation step here may be the interaction of a surface hole with the hydroxyl group of the alcohol forming a metal-oxo species with the removal of a proton (Scheme 2) [45]. This proton removal step becomes easier with increased carbon chain branching as well as with increased carbon chain length, because of the increased availability of adjacent removable protons. The higher the number of adjacent hydrogen atoms present, the easier is the removal and the greater would be the conversion. It was observed that presence of a benzene ring enhanced the conversion. The linking of phenyl rings of 1-phenlethanol to the $\mathrm{TiO}_{2}$ surface via a $\pi-\mathrm{OH}$ interaction, an inhibition effect may be produced, preventing phenyl group migration; the formation of phenyl ethanol hydroperoxide species, which may give acetophenone and water. This can be attributed to the electron-deficient nature of the benzene ring, which results in a reduced electron density at oxygen-hydrogen bond, thereby making the proton abstraction relatively easier. In gas phase processes, styrene has been formed from 1-phenylethanol due to the photocatalytic-induced dehydration of the alcohol [41].
Photooxidation of cumene to acetophenone in acetonitrile has been reported [49], where IR and XPS analysis of cumene adsorption on $\mathrm{TiO}_{2}$ have shown that an interaction of the benzene ring with surface $\mathrm{OH}$ groups takes place without appreciable dehydration or dehydroxylation of the surface. Acetophenone and $\mathrm{CO}_{2}$ were the only reaction products detected, and the reaction proceeds with the intermediate of a hydroperoxide.

3.3. Influence of Doping Concentration. Photocatalytic oxidation of 1-phenlethnol over raw nano-phase $\mathrm{TiO}_{2}$ in aqueous medium $(\mathrm{pH}=6.4)$ after 3 hours of run gave only $4 \%$ conversion. No significant difference in photoactivity was observed between the $\mathrm{TiO}_{2}$ prepared using flame aerosol method and the Degussa (P25). Reaction using both V and Fe-doped $\mathrm{TiO}_{2}$ gave higher conversions than the reaction with neat $\mathrm{TiO}_{2}$. Other studies have shown that metal-doped $\mathrm{TiO}_{2}$ have faster electron-hole recombination rate than the raw neat $\mathrm{TiO}_{2}$ including those doping on $\mathrm{TiO}_{2}$ surface by impregnation method [50]. The yield of acetophenone formed as a function of the amount of Fe- and V-doped on the $\mathrm{TiO}_{2}$ are shown in Figures 7 and 8, respectively. For both of $\mathrm{Fe}$ - and $\mathrm{V}$-doped $\mathrm{TiO}_{2}$ there were doping concentrations that gave optimal yields of acetophenone at the reaction time of 3 hours (Figures 7 and 8 ). The optimal doping amount for $\mathrm{Fe}$ is about $0.6 \% \mathrm{wt}$, and $15 \%$ yield of acetophenone, whereas the optimal concentration for $\mathrm{V}$-doped $\mathrm{TiO}_{2}$ of about $3 \mathrm{wt} \%$ gave $40 \%$ yield of acetophenone. Increasing or decreasing the metal-doping concentration lowered the catalyst activity. Vanadium doping greatly improved the photoactivity compared to those of pure or Fe-doped $\mathrm{TiO}_{2}$. Previous studies indicated that the formation of the photoactive complex by $\mathrm{Fe}^{3+}$ with organics play a key role in promoting photocatalytic reaction. Increasing $\mathrm{Fe}^{2+}$ of nano$\mathrm{TiO}_{2}$ attenuate the photocatalytic activity [51].

One of the possible reasons for the optimal doping concentration is the competing effects between the recombination rate of the electron and hole pairs on the catalyst surface, and the hole capture rate by the substrate. At low metal concentrations, the metal ions do not affect the bulk electronic structure of the semiconductor and its electronhole generation and separation capacity. As a result, the photoactivity slowly increases with doped metal concentration. At excess metal concentration, the metal ions may sharply increase the conductivity of the resulted materials and the recombination rate of the photogenerated electronhole pairs. Further increase of the doping concentration did not favor enhanced activity. It has been previously observed that incorporating cations of valence higher than that of the parent cation, such as $\mathrm{W}^{6+}, \mathrm{Ta}^{5+}$, and $\mathrm{Nb}^{5+}$, into the crystal matrix of $\mathrm{TiO}_{2}$ resulted in enhanced rates of water cleavage while the opposite is observed upon doping with cations of lower valence, such as $\mathrm{In}^{3+}, \mathrm{Zn}^{2+}$, and $\mathrm{Li}^{+}$[52]. The change in the photocatalytic activity is found to be dependent on the concentration and valence of the doping cations. Those results are explained in terms of alteration of the bulk electronic structure of the semiconductor, which influences its electron-hole generation and separation capacity under illumination. 


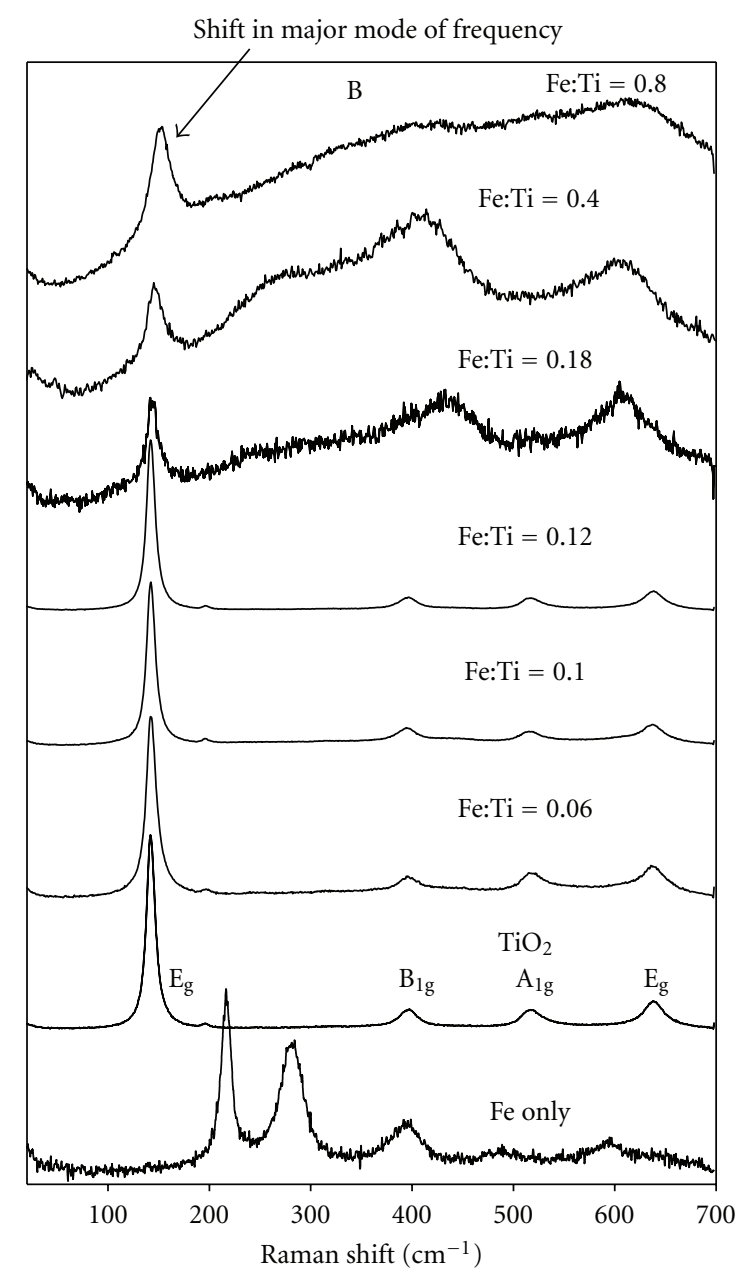

FIgURE 4: Raman spectra of nanostructured $\mathrm{TiO}_{2}$ flame aerosol synthesized doped with increasing amounts of Fe.

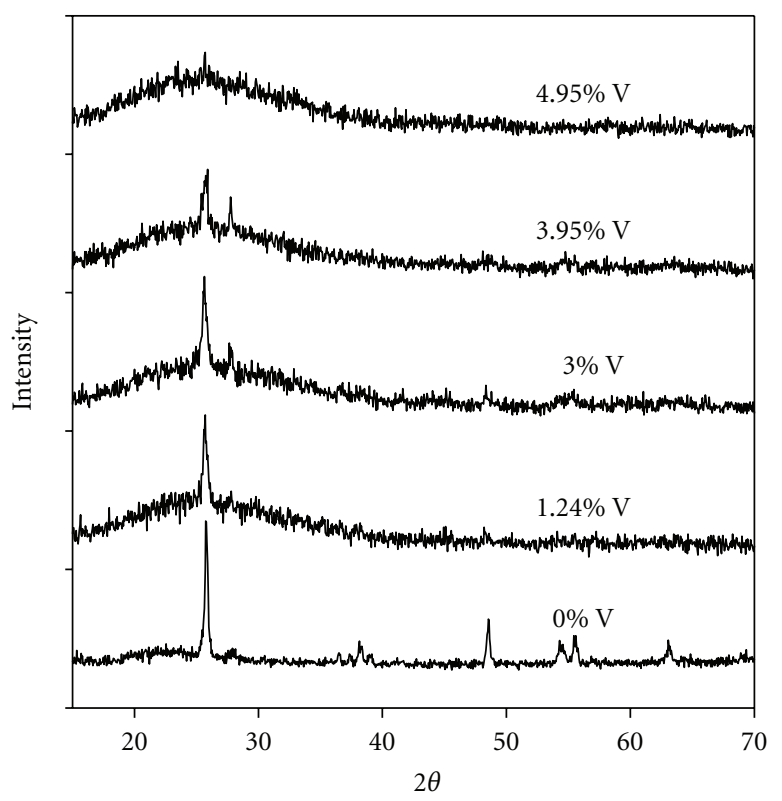

Figure 5: X-Ray diffraction patterns of flame aerosol prepared vanadium-deposited $\mathrm{TiO}_{2}$ at different doping concentrations.
Studies have also indicated problems concerning the stability of $\mathrm{Fe}-\mathrm{TiO}_{2}$ photocatalysts [53]. One major cause of a decrease in activity was photocorrosion leading to loss of Fe from the doped material

$$
\equiv \mathrm{Fe}(I I I)+e^{-} \longrightarrow \equiv \mathrm{Fe}(I I) \longrightarrow \mathrm{Fe}(I I)_{\text {solution }}
$$

competing with the activation of oxygen

$$
\mathrm{Fe}(I I)+\mathrm{O}_{2} \longrightarrow \mathrm{Fe}(I I I)-\mathrm{O}_{2}^{-} .
$$

With increased doping concentrations of both $\mathrm{Fe}$ and $\mathrm{V}$, the crystal structure and the morphology of catalyst have changed, and the size of catalyst particles decreased. As particle size decreased, the total catalyst surface area increased and the photogenerated electron density on the surface of each particle increased. This could have enhanced the photocatalytic reaction. However, with increase in the density of the electron-hole pairs, the possibility of the recombination of the electrons and holes also increases, which could be one of the reason that there is an optimal particles size that allowed highest conversion for the photocatalytic reaction.

Doping of metal ions in $\mathrm{TiO}_{2}$ can alter its bulk electronic structure, which influences its electron-hole generation and separation capacity under light illumination. Compared to $\mathrm{Fe}$-doped samples, higher concentrations of vanadium were doped to the $\mathrm{TiO}_{2}$ while maintaining the anatase crystal structure. On the other hand, V-doped photocatalyst has shown higher photocatalytic activity compared to Fe-doped and neat $\mathrm{TiO}_{2}$ samples. One of the possible reasons for the significant difference in the photocatalytic activity in the $\mathrm{TiO}_{2}$ doped with the two metals is that iron has larger electric conductivity than vanadium. Higher amounts of Fe allowed easier recombination of the electrons and holes which resulted in deleterious effects on the photoactivity of the doped $\mathrm{TiO}_{2}$. Vanadium has lower conductivity than iron therefore its concentration could be higher in the doped $\mathrm{TiO}_{2}$ and with little change in the catalytic materials' conductivity. Higher valence of $\mathrm{V}^{5+}$ could also help the photoactivity of the resulted catalyst [52].

3.4. Solvent Effect. The reaction in acetonitrile gave higher conversions than in water. The effects of using either water or acetonitrile as solvents on photocatalytic oxidation of 1phenylethanol studied are shown in Figures 7 and 8. For Vdoped $\mathrm{TiO}_{2}$, the increase in conversion of 1-phenylethanol with dopant concentration was 5 to 6 times higher in acetonitrile compared to the reaction in aqueous medium. Acetonitrile afforded much higher conversions compared to that in an aqueous medium because of the higher solubility of 1-phenyethanol in acetonitrile limiting the availability of the reactants in water leading to the low reaction rate [54]. The lower activity of the photocatalyst in water could also be attributable to the hydrophobic nature of $\mathrm{TiO}_{2}$ limiting the adsorption of 1-phenyethanol. Water molecules cover most of the titanium dioxide slurry surface due to their polarity, and the available surface for 1-phenylethanol directly interacts with the catalyst becoming less and the diffusion resistance is increased for both of the reactant and products. 


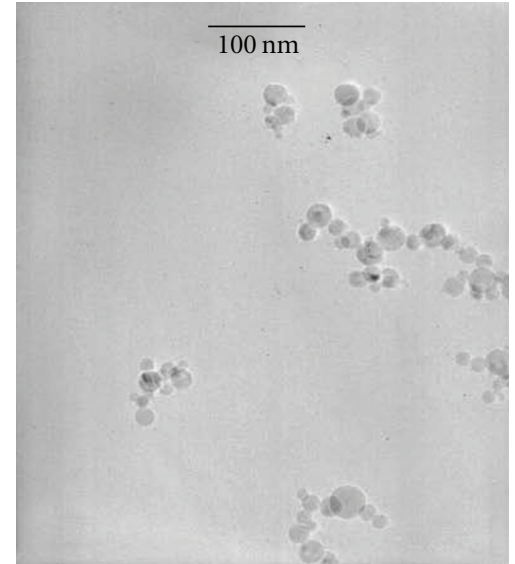

(a)

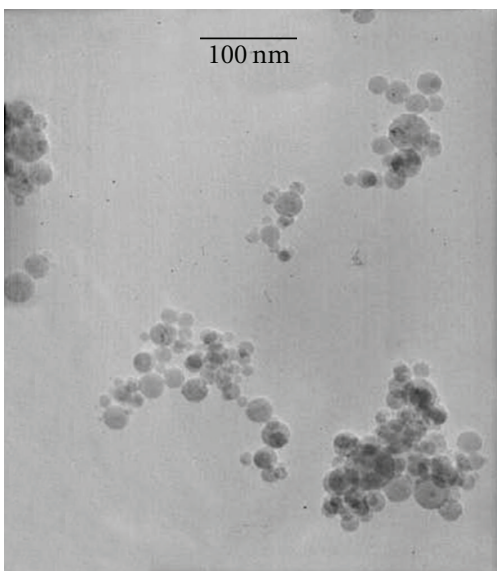

(c)

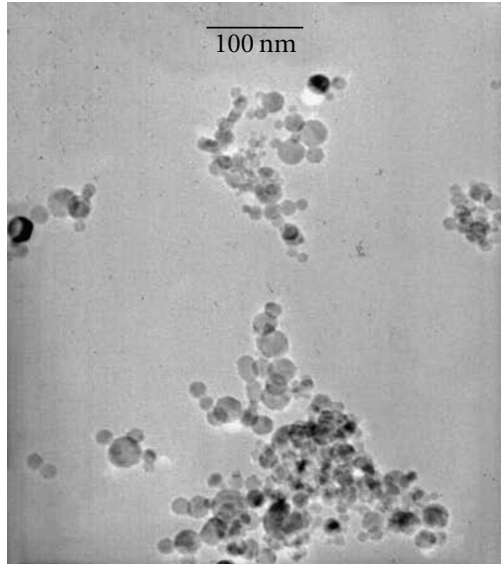

(b)

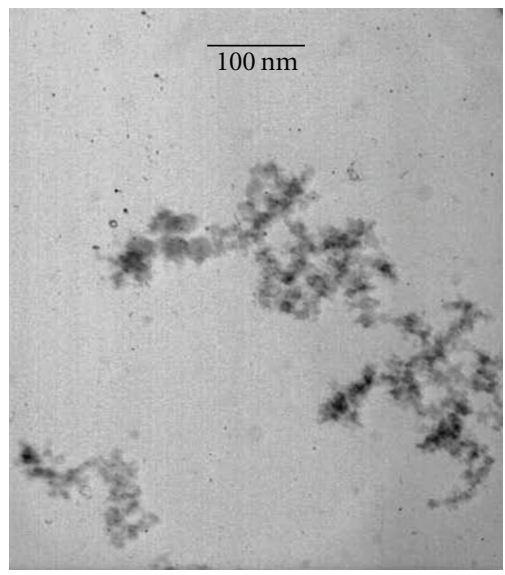

(d)

Figure 6: Transmission electron micrograph of the pure or doped $\mathrm{TiO}_{2}$ particles: (a) pure $\mathrm{TiO}_{2}$ particles using the TTIP Precursor; (b) $0.6 \mathrm{wt} \%$ Fe-doped $\mathrm{TiO}_{2}$ particles; (c) $2 \mathrm{wt} \%$ V-doped $\mathrm{TiO}_{2}$ particles; and (d) $2 \mathrm{wt} \% \mathrm{Fe}$-doped $\mathrm{TiO}_{2}$.

Selective adsorption of reactants on the $\mathrm{TiO}_{2}$ surface was found to account for differences in product selectivity [55]. Solvents such as chloroform strongly inhibit the photooxidation process due to the fact that it could compete with the hydrocarbon for oxidation and with $\mathrm{O}_{2}$ for reduction. Differences in reaction rates and chemoselectivity of products was also observed when aqueous medium was compared to those of organic solvents [56]. Solvent effects have been attributed to the stabilization of cation radicals intermediates. A highly efficient photocatalytic process of linear olefins epoxidation by molecular oxygen, using $\mathrm{TiO}_{2}$ suspensions, has been reported [57]. The yield (epoxide produced/olefin consumed) increased with a decrease of chain length and in solvents with high donor number as follows: hexane $<$ nitromethane $<$ acetonitrile $<$ butyronitrile. This effect may well be able to also be explained by a process that is mediated by the solvent hydroperoxides.

As the reaction time increased from three to six hours, the yield of oxidation product increased $25 \%$ using Fe-doped $\mathrm{TiO}_{2}$ and $40 \%$ for $\mathrm{V}$-doped $\mathrm{TiO}_{2}$. The yield for the vanadium doped catalyst system has higher conversion rate than the iron-doped catalyst system for the longer reaction time. This confirms the experimental data, as vanadium-doped $\mathrm{TiO}_{2}$ has higher activity.

\section{Conclusion}

The effects of metal doping on flame synthesized nanostructured $\mathrm{TiO}_{2}$ have been studied in order to extend its response to illumination with visible light. A flame aerosol codeposition method was used for the preparation of $\mathrm{V}$ and $\mathrm{Fe}$-doped $\mathrm{TiO}_{2}$. Partial oxidation of 1-phenylethano- to acetophenone was used as a probe reaction to study photocatalytic activity. The type and concentration of dopant have strong influence in improving or inhibiting photocatalytic activity partial photooxidation. Although $\mathrm{Fe}$ - and V-doped $\mathrm{TiO}_{2}$ did not show enhanced response to visible light, there are improvements in photoactivity of doped catalyst. The photocatalytic activity of $\mathrm{V}$ and $\mathrm{Fe}-\mathrm{TiO}_{2}$ materials depends markedly on the doping level. Relatively high amounts of iron $\left(5 \mathrm{wt} \%\right.$ in $\left.\mathrm{Fe}^{3+}\right)$ and vanadium $\left(6 \mathrm{wt} \%\right.$ in $\left.\mathrm{V}^{5+}\right)$ had adverse effect on the activity of $\mathrm{TiO}_{2}$ for 1-phenylethanol oxidation. However, positive effects are observed with a lower $\mathrm{Fe}^{3+}$ concentration $(0.5 \mathrm{wt} \%)$ and $\mathrm{V}^{5+}$ concentrations 


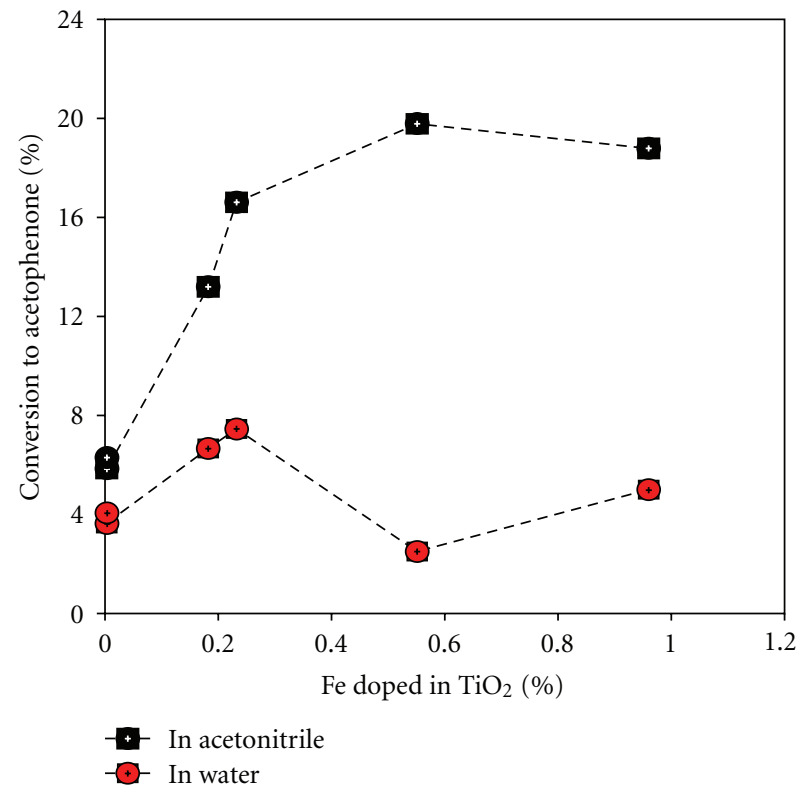

FIGURE 7: Conversion for yield of ketone formation and conversion of Fe-doped $\mathrm{TiO}_{2}$ for the different doping concentrations.

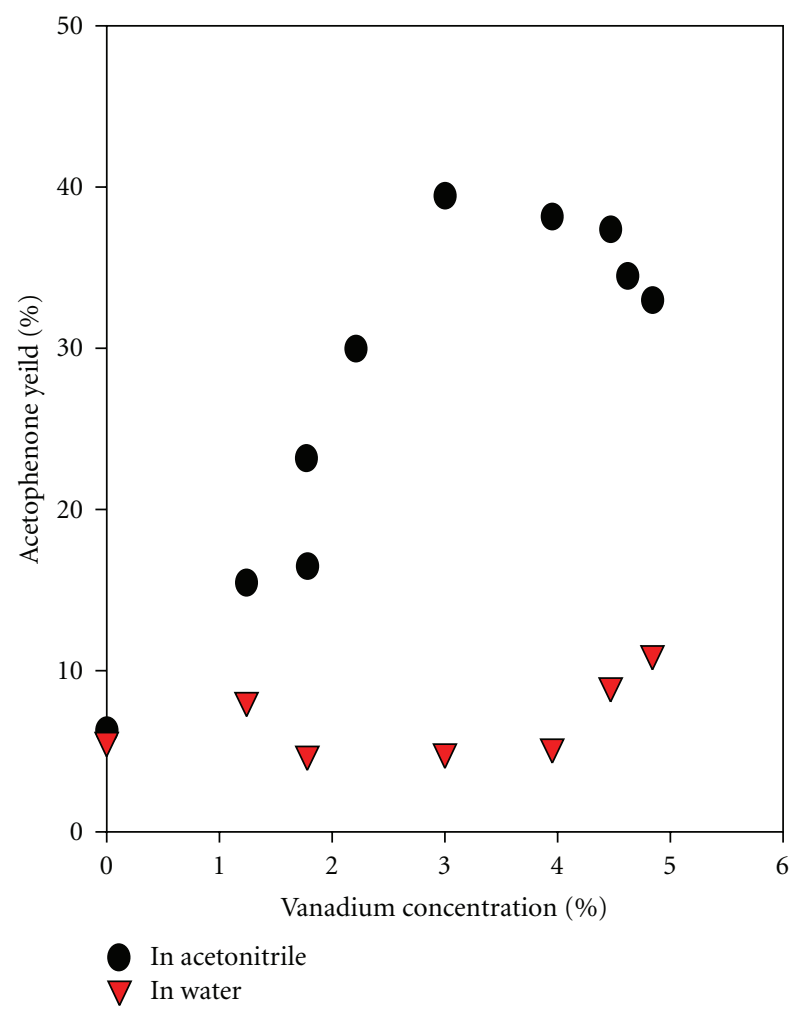

Figure 8: Conversion rate for ketone formation and conversion of vanadium-doped $\mathrm{TiO}_{2}$ for the different doping concentrations.

(3 wt $\%$ ), where the conversion of 1-phenylethanol increased by 2.5 and 6 folds, respectively, compared to undoped $\mathrm{TiO}_{2}$.

With the increase of the metal doping amount, the crystallinity of titanium dioxide decreased and the ratio of anatase-to-rutile in the product decreased. As the doping concentration increased, the resulting product from the flame process became amorphous fine powders, and the crystal patterns could not be detected by XRD, and Raman spectroscopy. These changes in physical properties of the $\mathrm{TiO}_{2}$ resulted in unique adsorption properties of organic substrates and allowed controlling the photocatalytic properties of the catalyst. Vanadium-doped $\mathrm{TiO}_{2}$ showed higher activity than that of iron-doped $\mathrm{TiO}_{2}$. An optimal doping concentration existed for both of the doping species in the applied photocatalytic reaction systems. The optimum doping concentration also depended on the type of solvent used for the photocatalytic reaction. The possible reasons for the optimal doping concentration have also been discussed. For the studied system, the one using acetonitrile as solvent has much higher conversions compared to the system using water as solvent.

\section{References}

[1] J. M. Herrmann, "Heterogeneous photocatalysis: fundamentals and applications to the removal of various types of aqueous pollutants," Catalysis Today, vol. 53, no. 1, pp. 115129, 1999.

[2] M. R. Hoffmann, S. T. Martin, W. Choi, and D. W. Bahnemann, "Environmental applications of semiconductor photocatalysis," Chemical Reviews, vol. 95, no. 1, pp. 69-96, 1995.

[3] J. A. Navío, G. Colón, M. I. Litter, and G. N. Bianco, "Synthesis, characterization and photocatalytic properties of iron-doped titania semiconductors prepared from $\mathrm{TiO}_{2}$ and iron (III) acetylacetonate," Journal of Molecular Catalysis A: Chemical, vol. 106, no. 3, pp. 267-276, 1996.

[4] S. Sakthivel, M. Janczarek, and H. Kisch, "Visible light activity and photoelectrochemical properties of nitrogendoped $\mathrm{TiO}_{2}$," Journal of Physical Chemistry B, vol. 108, no. 50, pp. 19384-19387, 2004.

[5] Y. Suda, H. Kawasaki, T. Ueda, and T. Ohshima, "Preparation of nitrogen-doped titanium oxide thin film using a PLD method as parameters of target material and nitrogen concentration ratio in nitrogen/oxygen gas mixture," Thin Solid Films, vol. 475, no. 1-2, pp. 337-341, 2005.

[6] J. C. Yu, W. Ho, J. Yu, H. Yip, K. W. Po, and J. Zhao, "Efficient visible-light-induced photocatalytic disinfection on sulfur-doped nanocrystalline titania," Environmental Science and Technology, vol. 39, no. 4, pp. 1175-1179, 2005.

[7] F. Fresno, C. Guillard, J. M. Coronado et al., "Photocatalytic degradation of a sulfonylurea herbicide over pure and tindoped $\mathrm{TiO}_{2}$ photocatalysts," Journal of Photochemistry and Photobiology A: Chemistry, vol. 173, no. 1, pp. 13-20, 2005.

[8] T. I. Halkides, D. I. Kondarides, and X. E. Verykios, "Catalytic reduction of $\mathrm{NO}$ by $\mathrm{C}_{3} \mathrm{H}_{6}$ over $\mathrm{Rh} / \mathrm{TiO}_{2}$ catalysts effect of Wcation doping of $\mathrm{TiO}_{2}$ on morphological characteristics and catalytic performance," Applied Catalysis B: Environmental, vol. 41, no. 4, pp. 415-426, 2003.

[9] S. M. Karvinen, "The effects of trace element doping on the optical properties and photocatalytic activity of nanostructured titanium dioxide," Industrial and Engineering Chemistry Research, vol. 42, no. 5, pp. 1035-1043, 2003.

[10] K. Palmisano, V. Augugliaro, A. Sclafani, and M. Schiavello, "Activity of chromium-ion-doped titania for the dinitrogen photoreduction to ammonia and for the phenol photodegradation," Journal of Physical Chemistry, vol. 92, no. 23, pp. 6710-6713, 1988. 
[11] T. Umebayashi, T. Yamaki, H. Itoh, and K. Asai, "Analysis of electronic structures of $3 \mathrm{~d}$ transition metal-doped $\mathrm{TiO}_{2}$ based on band calculations," Journal of Physics and Chemistry of Solids, vol. 63, no. 10, pp. 1909-1920, 2002.

[12] J. I. Choi, J. H. Han, and D. Y. Kim, "Effect of titania and lithia doping on the boundary migration of alumina under an electric field," Journal of the American Ceramic Society, vol. 86, no. 2, pp. 347-350, 2003.

[13] V. Guidi, M. C. Carotta, M. Ferroni, G. Martinelli, and M. Sacerdoti, "Effect of dopants on grain coalescence and oxygen mobility in nanostructured titania anatase and rutile," Journal of Physical Chemistry B, vol. 107, no. 1, pp. 120-124, 2003.

[14] S. Jeon and P. V. Braun, "Hydrothermal synthesis of Er-doped luminescent $\mathrm{TiO}_{2}$ nanoparticles," Chemistry of Materials, vol. 15, no. 6, pp. 1256-1263, 2003.

[15] H. Jiang and L. Gao, "Enhancing the UV inducing hydrophilicity of $\mathrm{TiO}_{2}$ thin film by doping Fe ions," Materials Chemistry and Physics, vol. 77, no. 3, pp. 878-881, 2003.

[16] A. Kumbhar and G. Chumanov, "Synthesis of iron(III)-doped titania nanoparticles and its application for photodegradation of sulforhodamine-B pollutant," Journal of Nanoparticle Research, vol. 7, no. 4-5, pp. 489-498, 2005.

[17] S. Mozia et al., "Decomposition of nonionic surfactant on a nitrogen-doped photocatalyst under visible-light irradiation," Applied Catalysis B-Environmental, vol. 55, no. 3, pp. 195-200, 2005.

[18] S. Yin, Y. Aita, M. Komatsu, J. Wang, Q. Tang, and T. Sato, "Synthesis of excellent visible-light responsive $\mathrm{TiO}_{2}-{ }_{x} \mathrm{~N}_{y}$ photocatalyst by a homogeneous precipitation- solvothermal process," Journal of Materials Chemistry, vol. 15, no. 6, pp. 674-682, 2005.

[19] H. Luo, T. Takata, Y. Lee, J. Zhao, K. Domen, and Y. Yan, "Photocatalytic activity enhancing for titanium dioxide by codoping with bromine and chlorine," Chemistry of Materials, vol. 16, no. 5, pp. 846-849, 2004.

[20] H. Wittmer, "Apparent band shift of Cr3+-doped titania as observed by photoacoustic and impedance spectroscopy," Zeitschrift Fur Physikalische Chemie-International Journal of Research in Physical Chemistry \& Chemical Physics, vol. 214, pp. 709-720, 2000.

[21] Y. Ma, X. T. Zhang, ZI. S. Guan, YA. A. Cao, and J. N. Yao, "Effects of zinc(II) and iron(III) doping of titania films on their photoreactivity to decompose rhodamine B," Journal of Materials Research, vol. 16, no. 10, pp. 2928-2933, 2001.

[22] F. Gracia, J. P. Holgado, A. Caballero, and A. R. GonzalezElipe, "Structural, optical, and photoelectrochemical properties of $\mathrm{M}+-\mathrm{TiO}_{2}$ model thin film photocatalysts," Journal of Physical Chemistry B, vol. 108, no. 45, pp. 17466-17476, 2004.

[23] K. Wilke and H. D. Breuer, "The influence of transition metal doping on the physical and photocatalytic properties of titania," Journal of Photochemistry and Photobiology A: Chemistry, vol. 121, no. 1, pp. 49-53, 1999.

[24] D. Dvoranová, V. Brezová, M. Mazúr, and M. A. Malati, "Investigations of metal-doped titanium dioxide photocatalysts," Applied Catalysis B: Environmental, vol. 37, no. 2, pp. 91-105, 2002.

[25] E. Piera, M. I. Tejedor-Tejedor, M. E. Zorn, and M. A. Anderson, "Relationship concerning the nature and concentration of $\mathrm{Fe}$ (III) species on the surface of $\mathrm{TiO}_{2}$ particles and photocatalytic activity of the catalyst," Applied Catalysis B: Environmental, vol. 46, no. 4, pp. 671-685, 2003.
[26] Z. M. Wang, G. Yang, P. Biswas, W. Bresser, and P. Boolchand, "Processing of iron-doped titania powders in flame aerosol reactors," Powder Technology, vol. 114, no. 1-3, pp. 197-204, 2001.

[27] J. J. Sene, W. A. Zeltner, and M. A. Anderson, "Fundamental photoelectrocatalytic and electrophoretic mobility studies of $\mathrm{TiO}_{2}$ and V-doped $\mathrm{TiO}_{2}$ thin-film electrode materials," Journal of Physical Chemistry B, vol. 107, no. 7, pp. 1597-1603, 2003.

[28] P. Falaras, I. M. Arabatzis, T. Stergiopoulos, and M. C. Bernard, "Enhanced activity of silver modified thin-film $\mathrm{TiO}_{2}$ photocatalysts," International Journal of Photoenergy, vol. 5, no. 3, pp. 123-130, 2003.

[29] C. Li, J. Wang, X. Wang, H. Chen, and W. Su, "Nonlinear electrical properties of Ta-doped titania capacitor-varistor ceramics," Materials Chemistry and Physics, vol. 74, no. 2, pp. 187-191, 2002.

[30] T. V. Nguyen, S. Kim, and O. B. Yang, "Water decomposition on $\mathrm{TiO}_{2}-\mathrm{SiO}_{2}$ and $\mathrm{RuS}_{2} / \mathrm{TiO}_{2}-\mathrm{SiO}_{2}$ photocatalysts: the effect of electronic characteristics," Catalysis Communications, vol. 5, pp. 59-62, 2004.

[31] K. T. Ranjit and B. Viswanathan, "Photocatalytic reduction of nitrite and nitrate ions over doped $\mathrm{TiO}_{2}$ catalysts," Journal of Photochemistry and Photobiology A: Chemistry, vol. 107, no. 13, pp. 215-220, 1997.

[32] Z. H. Yuan, J. H. Jia, and LI. D. Zhang, "Influence of co-doping of $\mathrm{Zn}(\mathrm{II})+\mathrm{Fe}(\mathrm{III})$ on the photocatalytic activity of $\mathrm{TiO}_{2}$ for phenol degradation," Materials Chemistry and Physics, vol. 73, no. 2-3, pp. 323-326, 2002.

[33] E. Sahle-Demessie, M. Gonzalez, Z. M. Wang, and P. Biswas, "Synthesizing alcohols and ketones by photoinduced catalytic partial oxidation of hydrocarbons in $\mathrm{TiO}_{2}$ film reactors prepared by three different methods," Industrial and Engineering Chemistry Research, vol. 38, no. 9, pp. 3276-3284, 1999.

[34] M. Anpo, T. Kawamura, S. Kodama, K. Maruya, and T. Onishi, "Photocatalysis on Ti-Al binary metal oxides: enhancement of the photocatalytic activity of $\mathrm{TiO}_{2}$ species," Journal of Physical Chemistry, vol. 92, no. 2, pp. 438-440, 1988.

[35] W. J. Stark and S. E. Pratsinis, "Aerosol flame reactors for manufacture of nanoparticles," Powder Technology, vol. 126, no. 2, pp. 103-108, 2002.

[36] K. Wegner and S. E. Pratsinis, "Flame synthesis of nanoparticles," Chimica Oggi, vol. 22, no. 9, pp. 27-29, 2004.

[37] M. J. Height, J. B. Howard, J. W. Tester, and J. B. V. Sande, "Flame synthesis of single-walled carbon nanotubes," Carbon, vol. 42, no. 11, pp. 2295-2307, 2004.

[38] W. Choi, A. Termin, and M. R. Hoffmann, "The role of metal ion dopants in quantum-sized $\mathrm{TiO}_{2}$ - correlation between photoreactivity and charge carrier recombination dynamics," Journal of Physical Chemistry, vol. 98, no. 51, pp. 13669-13679, 1994.

[39] S. Klosek and D. Raftery, "Visible light driven V-doped $\mathrm{TiO}_{2}$ photocatalyst and its photooxidation of ethanol," Journal of Physical Chemistry B, vol. 105, no. 14, pp. 2815-2819, 2002.

[40] M. Shui, L. H. Yue, and Z. D. Xu, "Photocatalytic activity of iron doping $\mathrm{TiO}_{2}$ prepared by several methods," Acta Physico-Chimica Sinica, vol. 17, no. 3, pp. 282-285, 2001.

[41] M. A. Fox and M. T. Dulay, "Heterogeneous photocatalysis," Chemical Reviews, vol. 93, no. 1, pp. 341-357, 1993.

[42] H. Kikkawa, B. O'Regan, and M. A. Anderson, "Photoelectrochemical properties of $\mathrm{Nb}$-doped $\mathrm{TiO}_{2}$ semiconductor ceramic membrane," Journal of Electroanalytical Chemistry and Interfacial Electrochemistry, vol. 309, no. 1-2, pp. 91-101, 1991. 
[43] S. I. Shah, W. Li, C. P. Huang, O. Jung, and C. Ni, "Study of $\mathrm{Nd}, \mathrm{Pd}, \mathrm{Pt}$, and Fe dopant effect on photoreactivity of $\mathrm{TiO}_{2}$ nanoparticles," Proceedings of the National Academy of Sciences of the United States of America, vol. 99, no. 9, pp. 6482-6486, 2002.

[44] U. R. Pillai and E. Sahle-Demessie, "Selective oxidation of alcohols in gas phase using light-activated titanium dioxide," Journal of Catalysis, vol. 211, no. 2, pp. 434-444, 2002.

[45] C. Minero, G. Mariella, V. Maurino, and E. Pelizzetti, "Photocatalytic transformation of organic compounds in the presence of inorganic anions. 1. Hydroxyl-mediated and direct electron-transfer reactions of phenol on a titanium dioxide -fluoride system," Langmuir, vol. 16, no. 6, pp. 2632-2641, 2000.

[46] V. Brezová, M. Čeppan, E. Brandšteterová, M. Breza, and L. Lapčík, "Photocatalytic hydroxylation of benzoic acid in aqueous titanium dioxide suspension," Journal of Photochemistry and Photobiology, A: Chemistry, vol. 59, no. 3, pp. 385-391, 1991.

[47] P. Calza, C. Minero, and E. Pelizzetti, "Photocatalytically assisted hydrolysis of chlorinated methanes under anaerobic conditions," Environmental Science and Technology, vol. 31, no. 8, pp. 2198-2203, 1997.

[48] N. Djeghri and S. J. Teichner, "Heterogeneous photocatalysis: the photooxidation of 2-methylbutane," Journal of Catalysis, vol. 62, no. 1, pp. 99-106, 1980.

[49] R. Wittenberg, M. A. Pradera, and J. A. Navio, "Cumene photo-oxidation over powder $\mathrm{TiO}_{2}$ catalyst," Langmuir, vol. 13, no. 8, pp. 2373-2379, 1997.

[50] A. Di Paola, E. García-López, S. Ikeda, G. Marc, B. Ohtani, and L. Palmisano, "Photocatalytic degradation of organic compounds in aqueous systems by transition metal doped polycrystalline $\mathrm{TiO}_{2}$," Catalysis Today, vol. 75, no. 1-4, pp. 8793, 2002.

[51] J. Araña, O. González Díaz, M. Miranda Saracho, J. M. Doña Rodríguez, J. A. Herrera Melián, and J. Pérez Peña, "Maleic acid photocatalytic degradation using $\mathrm{Fe}-\mathrm{TiO}_{2}$ catalysts. Dependence of the degradation mechanism on the $\mathrm{Fe}$ catalysts content," Applied Catalysis B: Environmental, vol. 36, no. 2, pp. 113-124, 2002.

[52] K. E. Karakitsou and X. E. Verykios, "Effects of altervalent cation doping of $\mathrm{TiO}_{2}$ on its performance as a photocatalyst for water cleavage," Journal of Physical Chemistry, vol. 97, no. 6, pp. 1184-1189, 1993.

[53] M. I. Litter and J. A. Navío, "Photocatalytic properties of irondoped titania semiconductors," Journal of Photochemistry and Photobiology A: Chemistry, vol. 98, no. 3, pp. 171-181, 1996.

[54] G. J. Ten Brink, I. W. C. E. Arends, and R. A. Sheldon, "Green, catalytic oxidation of alcohols in water," Science, vol. 287, no. 5458, pp. 1636-1639, 2000.

[55] C. B. Almquist and P. Biswas, "The photo-oxidation of cyclohexane on titanium dioxide: an investigation of competitive adsorption and its effects on product formation and selectivity," Applied Catalysis A: General, vol. 214, no. 2, pp. 259-271, 2001.

[56] F. Soana, M. Sturini, L. Cermenati, and A. Albini, "Titanium dioxide photocatalyzed oxygenation of naphthalene and some of its derivatives," Journal of the Chemical Society. Perkin Transactions 2, no. 4, pp. 699-704, 2000.

[57] T. Ohno, K. Nakabeya, and M. Matsumura, "Epoxidation of olefins on photoirradiated titanium dioxide powder using molecular oxygen as an oxidant," Journal of Catalysis, vol. 176, no. 1, pp. 76-81, 1998. 

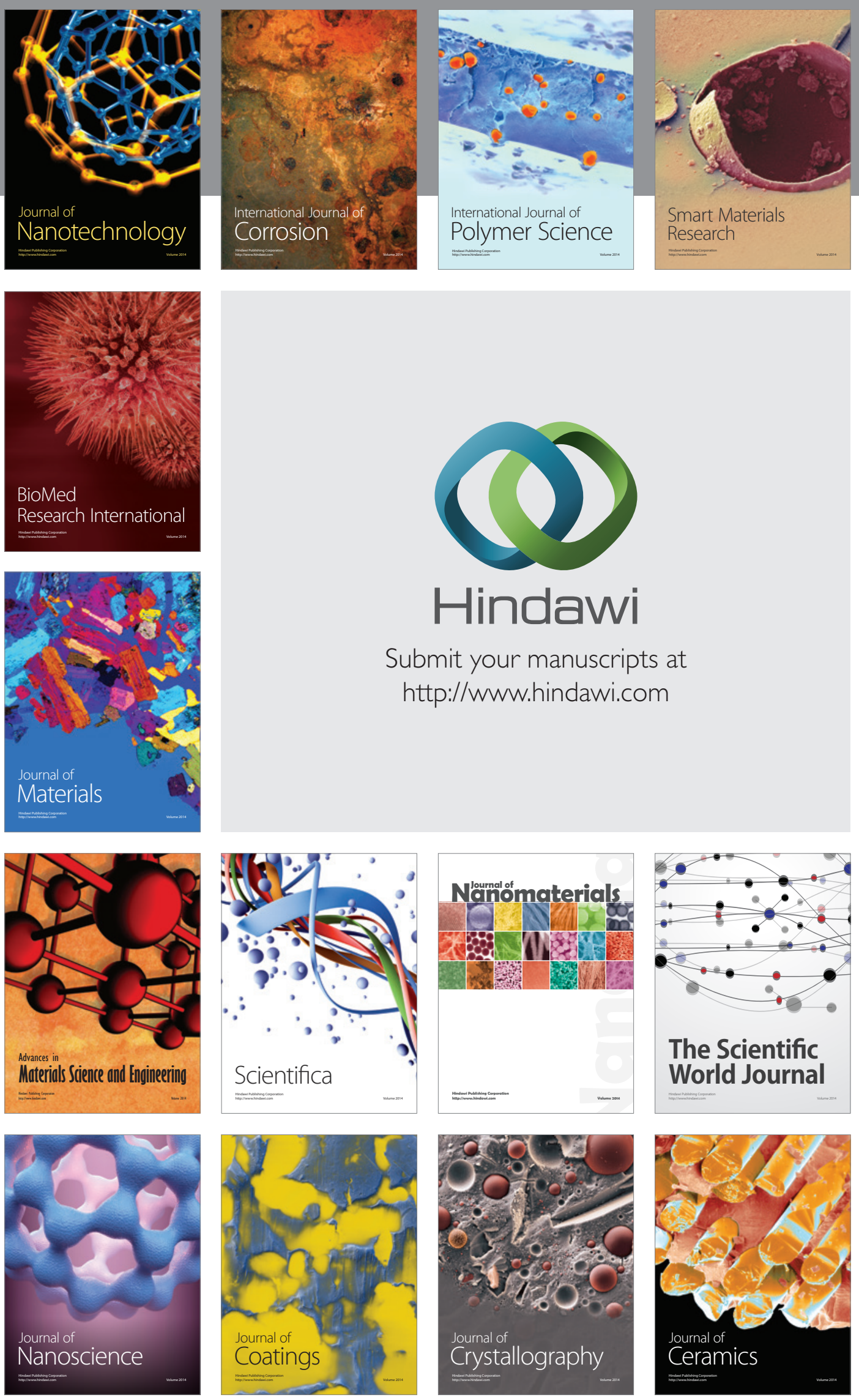

The Scientific World Journal

Submit your manuscripts at

http://www.hindawi.com

\section{World Journal}

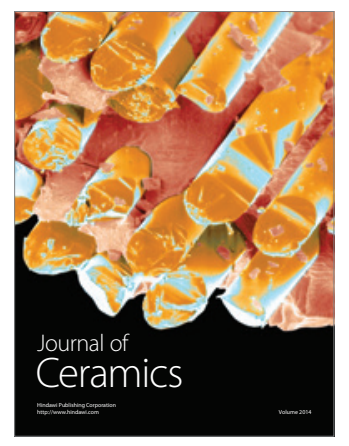

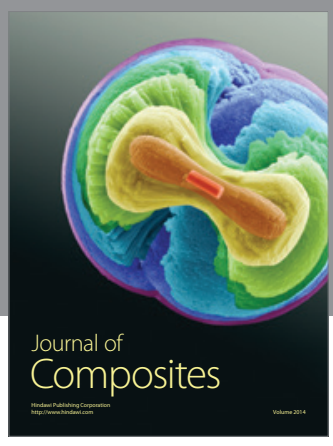
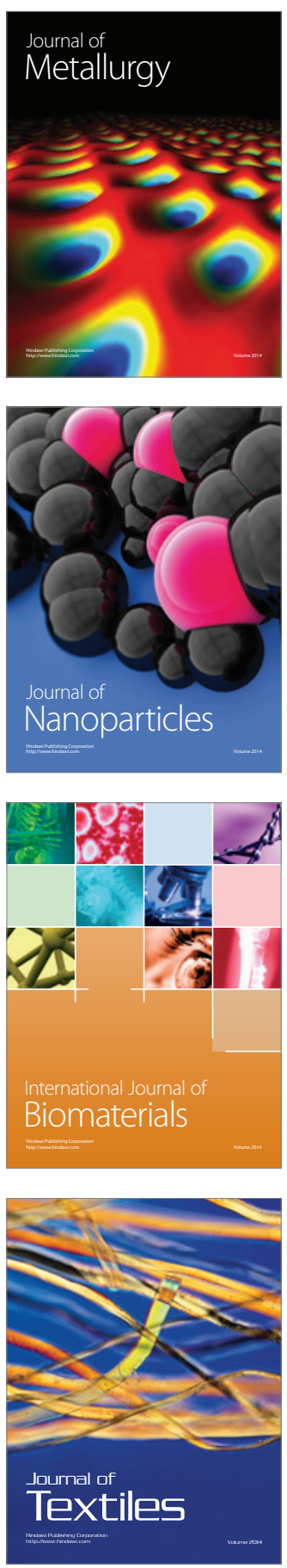